\title{
COMBINED DIAL SOUNDING OF OZONE, WATER VAPOUR AND AEROSOL
}

\author{
Thomas Trickl*, Hannes Vogelmann \\ Karlsruher Institut für Technologie, IMK-IFU, Kreuzeckbahnstr. 19, 82476 Garmisch-Partenkirchen, \\ Gernany,*e mail: thomas.trickl@kit.edu
}

\begin{abstract}
Routine high-quality lidar measurements of ozone, water vapour and aerosol at GarmischPartenkirchen since 2007 have made possible more comprehensive atmospheric studies and lead to a growing insight concerning the most frequently occurring long-range transport pathways. In this contribution we present as examples results on stratospheric layers travelling in the free troposphere for extended periods of time without eroding. In particular, we present a case of an intrusion layer that subsided over as many as fifteen days and survived the interference by strong Canadian fires. These results impose a challenge on atmospheric modelling that grossly overestimates free-tropospheric mixing.
\end{abstract}

\section{INTRODUCTION}

Differential absorption lidar (DIAL) methods have been applied in numerous atmospheric process and air-quality studies [1]. The most important species are ozone and water vapour, the free-tropospheric concentrations of other chemically relevant species such as $\mathrm{NO}$ or $\mathrm{NO}_{2}$ mostly being too low for. In the GarmischPartenkirchen area (Bavarian Alps, Germany) IMK-IFU has developed three DIAL systems for ozone and water vapour $[2,3,4,5]$ that have been extensively used in focussed atmospheric investigations. In 2007 a programme of routine measurements of ozone, water vapour and aerosol was started. By combining the measurements for these three species enhanced information for the atmospheric studies has been obtained. In this contribution we give examples of the scientific work related to these measurements.

\section{METHODS}

The ozone DIAL is located at IMK-IFU (Garmisch-Partenkirchen) at an altitude of $740 \mathrm{~m}$ a.s.l. It is a three-wavelength system based on stimulated Raman shifting the $248.50 \mathrm{~nm}$ output of a $\mathrm{KrF}$ laser (Lambda Physik, LPX250; operated at $400 \mathrm{~mJ} /$ pulse and $99 \mathrm{~Hz}$ repetition rate) in $\mathrm{H}_{2}$ and
$\mathrm{D}_{2}$. Ozone is calculated for the wavelength combinations $277 \mathrm{~nm}-313 \mathrm{~nm}, 292 \mathrm{~nm}-313 \mathrm{~nm}$ and, in the presence of aerosol [5], $277 \mathrm{~nm}-292 \mathrm{~nm}$. This allows internal quality assurance. Two Newtonian receivers $(0.13 \mathrm{~m}$ and $0.50 \mathrm{~m}$ diameter, respectively) have been used for dividing the eightdecade dynamic range [2]. For both the near-field and the far-field detection systems $1.1-\mathrm{m}$ Wadsworth-type grating spectrographs with a spectral resolution of $0.35 \mathrm{~nm}$ are used. The H5783P-06 Hamamatsu photomultiplier tubes used since 1996 were recently replaced by the successor model R7400U-03 with actively stabilized sockets provided by Romanski Sensors. Licel 12-bit, $20 \mathrm{MHz}$ transient digitizers with custom-made ground-free input are used for all six channels. With just minor smoothing (50 $\mathrm{m}$ range resolution [7]) the signals exhibit a noise level of about $1 \times 10^{-6}$ of the input voltage range, a major step forward in signal quality, making single photon counting almost unnecessary. The uncertainty of the ozone mixing ratios is $2-3 \mathrm{ppb}$ in the lower troposphere and 5-10 ppb in the upper troposphere due to the use of $292 \mathrm{~nm}$ as the "on" wavelength. A detailed system publication is in preparation.

Because of the excellent signal quality aerosol structures corresponding to backscatter coefficients of less than $1 \times 10^{-7} \mathrm{~m}^{-1} \mathrm{sr}^{-1}$ can be resolved at $313 \mathrm{~nm}$ within most of the troposphere. In this way at least some substitution of our non-funded high-spectral-resolution aerosol lidar [8] has been possible.

The water-vapour DIAL [5] is located at $2675 \mathrm{~m}$ a.s.l. in the top laboratory of the nearby Schneefernerhaus high-altitude research station (UFS). It is operated with typically $100 \mathrm{~mJ}$ from a $250-\mathrm{mJ}$ flashlamp-pumped Ti:sapphire laser with a repetition rate of $20 \mathrm{~Hz}$ determined by the pump laser of the two oscillators (Continuum, Powerlite 8020). The oscillators are widely tunable single-longitudinal-mode optical parametric oscillators (Continuum, Mirage). Several wavelength pairs next to $817 \mathrm{~nm}$ are used, depending on the humidity conditions. The absorption cross sections of Ponsardin 


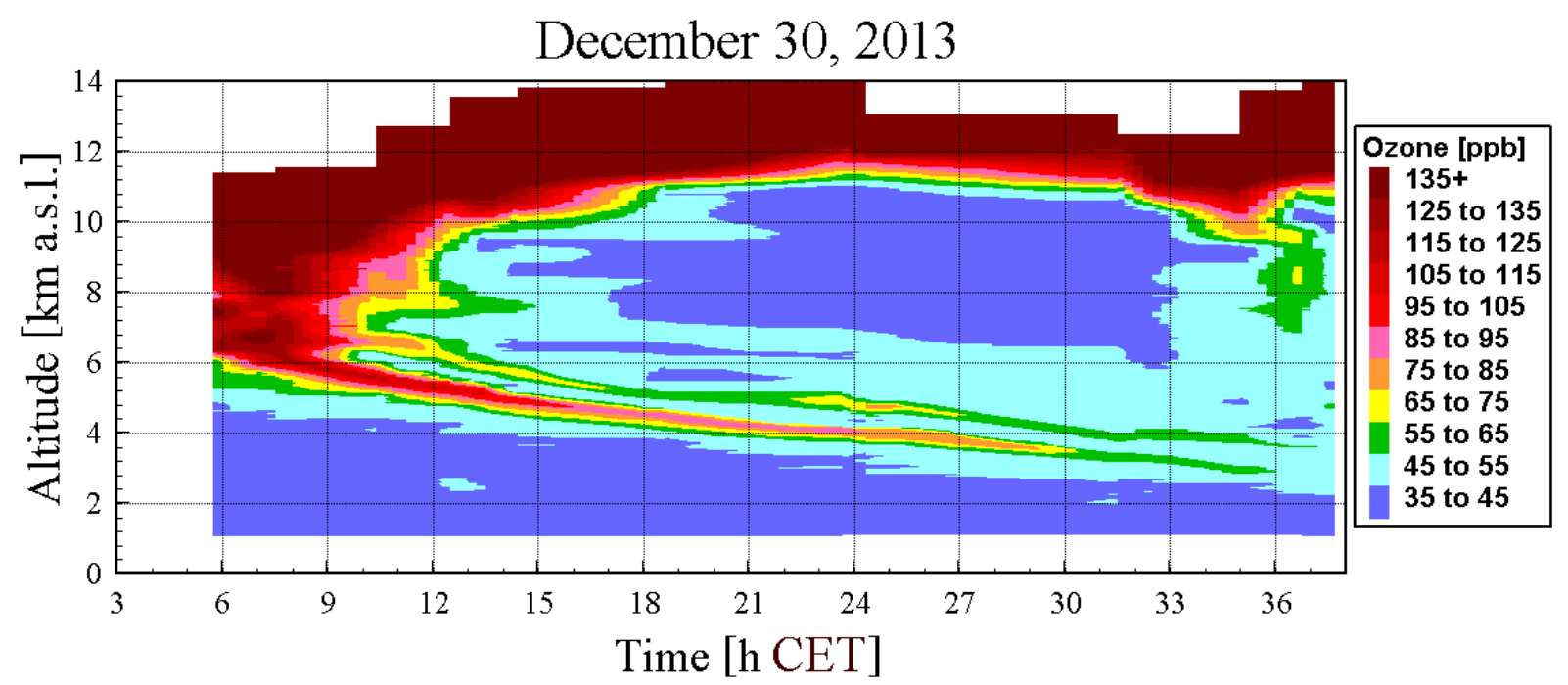

Fig. 1: Example of two parallel intrusion layers registered with the ozone DIAL; no $\mathrm{H}_{2} \mathrm{O}$ measurements were possible because UFS was closed on these days. The minimum relative humidity of the Munich radiosonde (station 10868) in both layers was $1 \%$ which, for unknown reasons, is the lowest value listed.

and Browell [9] have been used and verified to be better than the 2008 HITRAN values (e.g., $[10,11])$. A 0.65 -m-diameter Newtonian receiver collects the backscattered radiation that is separated into near- and far-field channels by a combination of a $1-\%$ beam splitter and an edge in a focus of the far-field channel. Avalanche photodiodes (APDs; Licel) and the same transient digitizer type as in the case of the ozone DIAL are used. The performance is currently limited by the noise from the APD modules and a laser power below the principal capability of the system [5]. A vertical range up to the tropopause region is achieved even during daytime. Up to about $7 \mathrm{~km}$ a.s.l. an uncertainty of $5 \%$ and no bias exceeding $1 \%$ have been demonstrated.

\section{RESULTS}

The measurements of ozone, water vapour and aerosol allow distinguishing between air from a remote boundary layer, characterized by the presence of particles, or from the stratosphere, characterized by low humidity and enhanced ozone. It is interesting to note that we have seen much less high-ozone structures in the free troposphere related to intercontinental transport than in the late 1990s and slightly afterwards. By contrast, most pronounced ozone peaks could be traced back to the stratosphere with travel times between two and fifteen days.

Meanwhile, stratospheric air intrusions have been observed on more than 300 days with one of the two DIAL systems or both. The structures and layer widths look quite different. One spectacular example is shown in Fig. 1. On about $60 \%$ of the measurement days stratospheric layers could be observed demonstrating that the ozone import from the stratosphere is by no means negligible as frequently claimed. Most astonishingly the humidity level in intrusion layers reaching the lower troposphere has been found to range mostly between 0 and $2 \%$, much lower than recorded by the in-situ instrumentation at Alpine summit levels [12]. Our $\mathrm{H}_{2} \mathrm{O}$ results clearly demonstrate that ozone mixing ratios of sometimes just $60 \mathrm{ppb}$ are not caused by mixing of the surrounding tropospheric air into these layers.

A summary of the analysis of about 80 intrusion days with the water-vapour DIAL is given in Fig. 2. Three ranges of travel times are distinguished by estimates from four-day forward trajectory plots daily received for stratospheric intrusion forecasts $[12,13,14]$ and from $315-\mathrm{h}$ backward runs with the HYSPLIT trajectory model (http://ready.arl.noaa.gov/ HYSPLIT traj.php). The results show that the probability of tropospheric admixture grows with the travel time in the troposphere. However, even for the longest travel times some layers do not change their lower-stratospheric characteristics.

A particularly intriguing example has been observed on July 16, 2013. July 2013 was characterized by very strong smoke from boreal North America sometimes filling a major part of the troposphere. On July 16, a thin smoke layer directly hit the Zugspitze summit (2962 m) and, therefore, could be observed at UFS $(2670 \mathrm{~m})$. The $313-\mathrm{nm}$ aerosol backscatter coefficients reached $1.2 \times 10^{-5}$ $\mathrm{m}^{-1} \mathrm{sr}^{-1}$ (Fig. 3), in agreement with the observed 
horizontal visual range of less than $10 \mathrm{~km}$. Ozone was just slightly enhanced, as confirmed by the UFS measurements, but the humidity values revealed by the $\mathrm{H}_{2} \mathrm{O}$ DIAL were almost zero (Fig. 4 ), which strongly suggests a stratospheric origin.
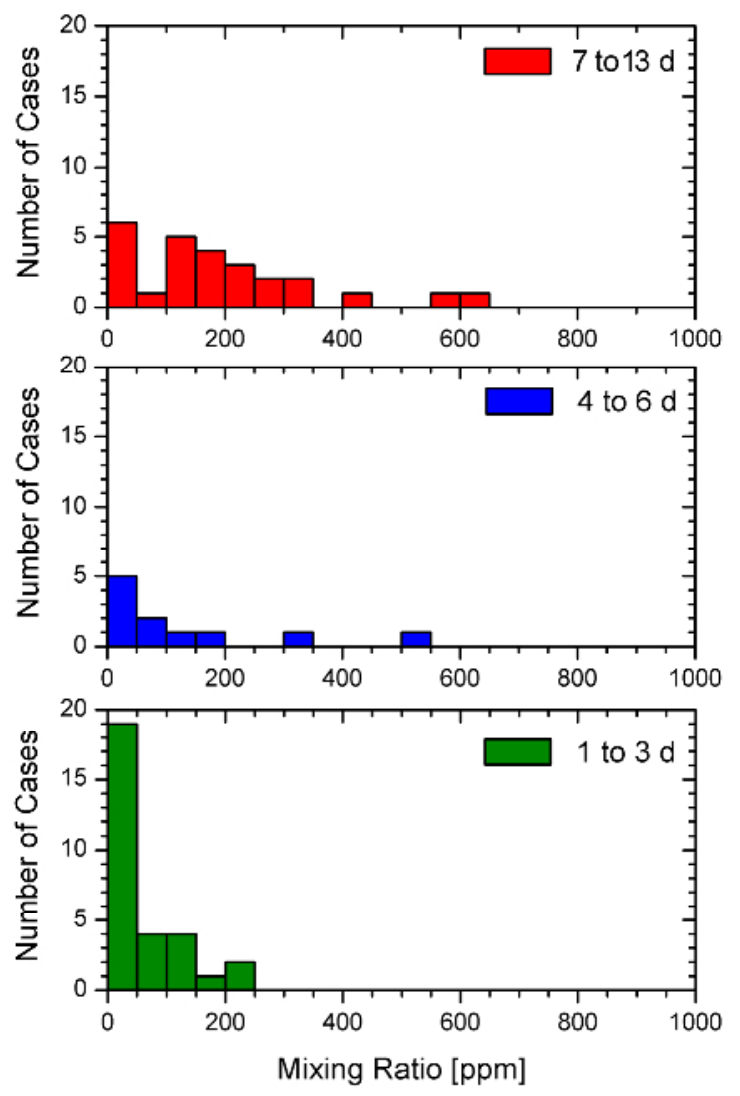

Fig. 2: Water-vapour mixing ratio at the centre of stratospheric air intrusion layers for different travel times [12] (for details see text)

HYSPLIT calculations extended to more than the maximum $315 \mathrm{~h}$ for a single run revealed a very slow subsidence from about $9 \mathrm{~km}$ over at least 15 $\mathrm{d}$, from Siberia via parts of the "road of fire" that had formed between Alaska and Eastern Canada to Europe. The backward trajectory bundle stayed unbelievably coherent on the way around the northern hemisphere.

It is difficult understand the extreme dryness and narrow structure of the smoke layer at $3.2 \mathrm{~km}$ on July 16. A strong perturbation of a thin atmospheric layer by a hot ascending air mass would be expected to occur. Thus, it is more likely that the stratospheric air tongue intersected a smoke column in a later, rather stationary phase. Low-humidity conditions are a prerequisite of pronounced forest fires. Dry air would not significantly change the $\mathrm{H}_{2} \mathrm{O}$ content of the intrusion layer. Alternatively, sedimentation of heavy particles into the layer could be thought of.

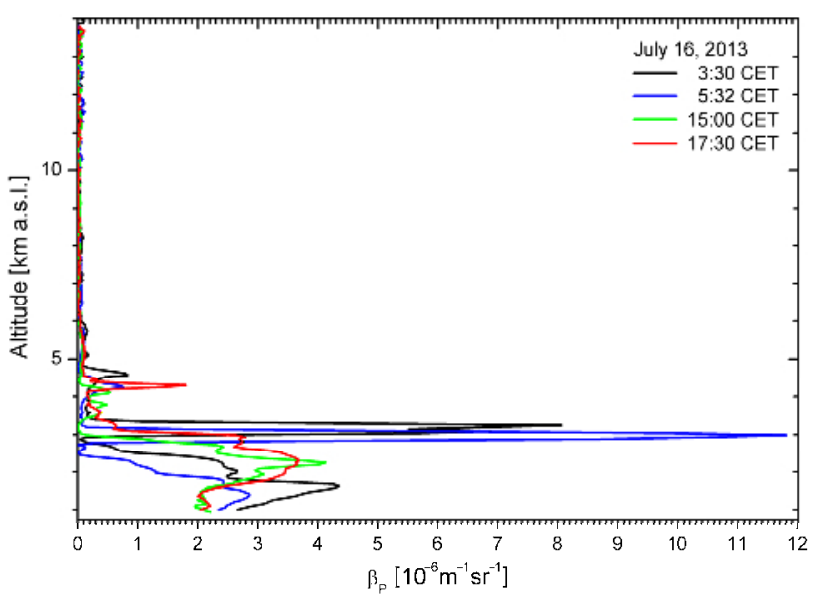

Fig. 3: 313-nm aerosol backscatter coefficients on July 16, 2013, showing a pronounced Canadian smoke plume at the altitude of the Zugspitze peak (2962 m a.s.1.) next to Garmisch-Partenkirchen

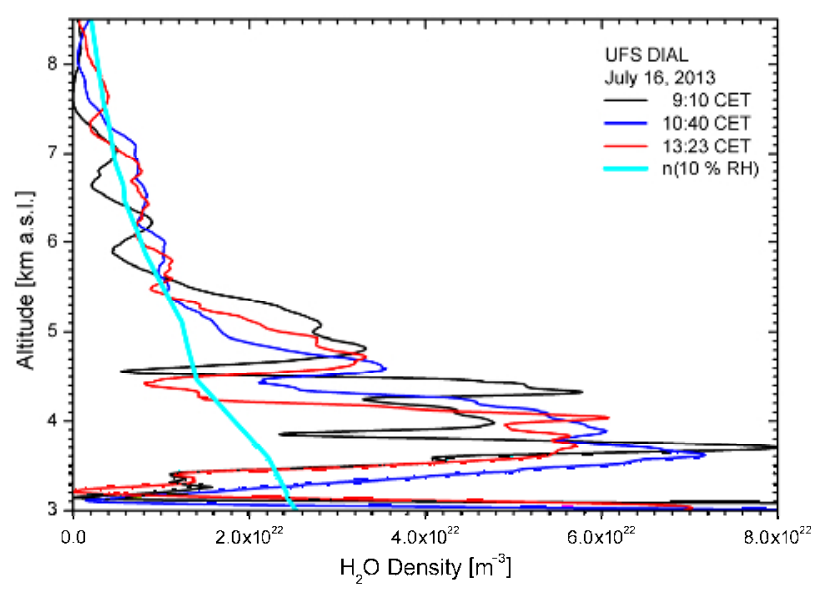

Fig. 4: Three water-vapour profiles from the $\mathrm{H}_{2} \mathrm{O}$ DIAL at UFS on July 16, 2013, showing the extreme dryness in the lower smoke layer in Fig. 3

\section{ACKNOWLEDGEMENTS}

The authors thank H. P. Schmid for his support. L. Ries made available in-situ data from the Global Atmosphere Watch laboratory at UFS, and M. Sprenger has maintained the invaluable intrusion forecast service over many years. The support by the UFS team is gratefully acknowledged. This work contributes to the European Aerosol Research Lidar Network, recently partly supported by the European Union within the ACTRIS project. 


\section{REFERENCES}

[1] Trickl, T., 2010: Tropospheric trace-gas measurements with the differential-absorption lidar technique, pp. 87-147 in: Recent Advances in Atmospheric Lidars, L. Fiorani, V. Mitev, Eds., INOE Publishing House, Bucharest (Romania), Series on Optoelectronic Materials and Devices, Vol. 7, ISSN 1584-5508, ISSN 978-973-88109-6-9; a revised version can be obtained from the author (thomas.trickl@kit.edu).

[2] Kempfer, U., W. Carnuth, R. Lotz, T. Trickl, 1994: A wide-range UV lidar system for tropospheric ozone measurements: Development and application, Rev. Sci. Instrum. 65, 3145-3164

[3] Eisele, H., T. Trickl, 1997: Second Generation of the IFU Stationary Tropospheric Ozone Lidar, pp. 379-382 in: Advances in Atmospheric Remote Sensing with Lidar, Selected Papers of the $18^{\text {th }}$ International Laser Radar Conference, A. Ansmann, R. Neuber, P. Rairoux, U. Wandinger, Eds., Springer (Berlin, Heidelberg, New York)

[4] Brenner, P., O. Reitebuch, K. Schäfer, T. Trickl, A. Stichternath, 1997: A Novel Mobile Verticalsounding System for Ozone Studies in the Lower Troposphere, pp. 383-386 in: Advances in Atmospheric Remote Sensing with Lidar, see [3].

[5] Vogelmann, H., T. Trickl, 2008: Wide-range sounding of free-tropospheric water vapor with a differential-absorption lidar (DIAL) at a high-altitude station, Appl. Opt. 47, 2116-2132

[6] Eisele, H., T. Trickl, 2005: Improvements of the aerosol algorithm in ozone-lidar data processing by use of evolutionary strategies, Appl. Opt. 44, 2638-2651

[7] VDI guideline 4210, Part 1, 1999: Remote Sensing: Atmospheric measurements with LIDAR, Measuring gaseous air pollution with DAS LIDAR, Verein Deutscher Ingenieure (VDI), (Düsseldorf, Germany), 47 pp.

[8] Giehl, H., T. Trickl, 2010: Testing the IFU HighSpectral-Resolution Lidar at the 2009 Leipzig Field Campaign, pp. 920-923 in: Proceedings of the $25^{\text {th }}$ International Laser Radar Conference, G.
Matvienko, A. Zemlyanov, Eds., published by V. E. Zuev Institute of Optics (Tomsk, Russia)

[9] Ponsardin, P. L., E. V. Browell, 1997: Measurements of $\mathrm{H}_{2}{ }^{16} \mathrm{O}$ linestrengths and air-induced broadenings and shifts in the $815 \mathrm{~nm}$ spectral region, J. Mol. Spectrosc. 185, 58-70.

[10] Wirth, M., A. Fix, G. Ehret, J. Reichardt, R. Begie, D. Engelbart, H. Vömel, B. Calpini, G. Romanens, A. Apituley, K. M. Wilson, H. Vogelmann, T. Trickl, 2009: Intercomparison of Airborne Water Vapour DIAL Measurements with Ground Based Remote Sensing and Radiosondes within the Framework of LUAMI 2008, Contribution S07-P01-1 (3 pp.) in: Proceedings of the $8^{\text {th }}$ International Symposium on Tropospheric Profiling (ISTP2009), Delft (The Netherlands), A. Apituley, H. W. J. Russchenberg, W. A. A. Monna, Eds., RIVM (The Netherlands, 2009), http://www.knmi.nl/ apituley/files/ istp8/, ISBN 978-90-6960-233-2

[11] Vogelmann, H., R. Sussmann, T. Trickl, T. Borsdorff, 2011: Intercomparison of atmospheric water vapor soundings from the differential absorption lidar (DIAL) and the solar FTIR system on Mt. Zugspitze, Atmos. Meas. Technol. 4, 835-841

[12] Trickl, T., H. Vogelmann, H. Giehl, H. E. Scheel, M. Sprenger, A. Stohl, 2014: How stratospheric are deep stratospheric intrusions? Atmos. Chem. Phys. 14, 9941-9961

[13] Zanis, P., T. Trickl, A. Stohl, H. Wernli, O. Cooper, C. Zerefos, H. Gaeggeler, A. Priller, C. Schnabel, H. E. Scheel, H. J. Kanter, L. Tobler, P. W. Kubik, P. Cristofanelli, C. Forster, P. James, E. Gerasopoulos, A. Delcloo, A. Papayannis, H. Claude, 2003: Forecast, observation and modelling of a deep stratospheric intrusion event over Europe, Atmos. Chem. Phys. 3, 763-777

[14] Trickl, T., H. Feldmann, H.-J. Kanter, H. E. Scheel, M. Sprenger, A. Stohl, H. Wernli, 2010: Deep stratospheric intrusions over Central Europe: case studies and climatological aspects, Atmos. Chem. Phys. 10, 499-524 